\title{
A New Maraging Stainless Steel with Excellent Strength-Toughness-Corrosion Synergy
}

\author{
Jialong Tian ${ }^{1,2}$, Wei Wang ${ }^{2, *}$, M. Babar Shahzad ${ }^{2}$, Wei Yan ${ }^{2}$, Yiyin Shan ${ }^{2}$, Zhouhua Jiang ${ }^{3}$ and \\ Ke Yang ${ }^{2}$ \\ 1 School of Materials Science and Engineering, Northeastern University, Shenyang 110004, China; \\ jltian12s@imr.ac.cn \\ 2 Institute of Metal Research, Chinese Academy of Sciences, Shenyang 110016, China; \\ babar@imr.ac.cn (M.B.S.); weiyan@imr.ac.cn (W.Y.); yyshan@imr.ac.cn (Y.S.); kyang@imr.ac.cn (K.Y.) \\ 3 School of Metallurgy, Northeastern University, Shenyang 110004, China; jiangzh@smm.neu.edu.cn \\ * Correspondence: wangw@imr.ac.cn; Tel.: +86-24-8397-8745
}

Received: 17 October 2017; Accepted: 8 November 2017; Published: 10 November 2017

\begin{abstract}
A new maraging stainless steel with superior strength-toughness-corrosion synergy has been developed based on an innovative concept of alloy design. The high strength-toughness combination is achieved by forming dispersive nano-sized intermetallic compounds in the soft lath martensitic matrix with a slight amount of residual austenite. The good corrosion resistance is guaranteed by exactly controlling the Co content based on understanding the synergistic effect between $\mathrm{Co}$ and $\mathrm{Cr}$. The fine structure characteristics of two dominant strengthening precipitations including $\mathrm{Ni}_{3} \mathrm{Ti}$ and Mo-rich phases were finely characterized associated with transmission electron microscope (TEM) and atom probe tomography (APT) analyses. The relationship among microstructure, strength and toughness is discussed. The precipitation mechanism of different precipitates in the new maraging stainless steel is revealed based on the APT analysis.
\end{abstract}

Keywords: maraging stainless steel; alloy design; strength and toughness; corrosion resistance; atomic probe tomography; precipitation mechanism

\section{Introduction}

Maraging stainless steels (MSS) are a class of high strength stainless steels with excellent comprehensive performances including high strength, superior corrosion resistance and good weldability, etc. [1-5]. Since the first maraging stainless steel was developed by Carnegie Illionois Steel Corporation in 1946 to meet military demands, many efforts have been successfully realized to improve its performance [6-14]. Nowadays, new maraging stainless steel, as an important candidate material to ensure the lower energy consumptions and pollution reduction owing to its unique combination of properties including high strength, high toughness and superior corrosion resistance, is attracting much greater attention. However, a significant bottleneck that hinders the future applications of maraging stainless steels as potential structural materials is the trade-off dilemma among their strength, fracture toughness and corrosion resistance.

As far as the strength of MSS is considered, different methods have been tried to increase their strength, such as multiple-phase strengthening [1-3], co-precipitation of nano-scale particles [7,8], and minimal lattice misfit between matrix and precipitate [13]. Meanwhile, attentions have been concentrated on characterizing the relationship between strength and precipitate, for instances, the lattice structure, orientation relationship and evolution process during aging treatment. Besides the strength of MSS, corrosion resistance is another important and particularly critical property for future applications, because more and more materials will be subjected to extreme mechanical loads and harsh environmental conditions where corrosion is an important issue. Unfortunately, MSS with 
high strength is always accompanied with a loss in toughness or corrosion resistance. In general, two methods are usually considered to increase the strength of MSS. One is to add carbon (C) to strengthen the lath martensitic matrix. However, higher content of $C$ could present a gradual incremental trend to form chromium carbides, which are harmful for both toughness and corrosion resistance $[15,16]$. Another method is to add more strengthening elements to increase the strength by precipitation hardening. However, most strengthening elements such as $\mathrm{Mo}$, $\mathrm{Ti}$ and $\mathrm{Al}$ are also ferrite formation elements and they will promote the formation of delta-ferrite, which is harmful to the toughness. Different from those strengthening elements, Co is often added to increase the strength of maraging stainless steel by its synergistic effect with strengthening elements such as Ti and Mo [11-14]. However, $\mathrm{Co}$ also accelerates the spinodal decomposition of $\mathrm{Cr}$ atoms during the aging process, which could deteriorate the corrosion resistance [17].

In this study, a new maraging stainless steel, defined as "IMR steel" (Steel from the Institute of Metal Research), was developed based on an innovative concept of synergistic effect of multiple elements in maraging stainless steels. The microstructure of quenched IMR steel was comprised of soft lath martensitic and residual austenite. In the subsequent aging process, large amounts of nano-sized intermetallic compounds precipitate in the matrix. The IMR steel exerts a high strength in combination with high toughness and good corrosion resistance, showing outstanding performance compared with other commercial maraging stainless steels. It is expected that the new maraging steel will have potential applications in the aircraft, power generation, tools and automotive industries.

\section{Alloy Design}

According to the conventional "stainless theory", it is generally believed that $\mathrm{Cr}$ must be added to above $11 \mathrm{wt} \%$ to impart "stainlessness" to steels. At this Cr level, an adherent and self-healing chromium oxide can be formed on the steel surface in the relatively benign corrosive environment, especially with $13 \mathrm{wt} \% \mathrm{Cr}$ addition in steel, and superior corrosion resistance could be achieved [18]. Thus, the $\mathrm{Cr}$ content has been set as $13 \mathrm{wt} \%$ to guarantee a superior corrosion resistance.

Co is a key element in maraging stainless steel since it controls the balance between strength and corrosion resistance. According to previous research [17], when Co content was $13 \mathrm{wt} \%$, the MSS showed a poor corrosion resistance even with $13 \mathrm{wt} \% \mathrm{Cr}$ addition. When Co content was decreased to $7 \mathrm{wt} \%$, the MSS showed a good corrosion resistance in $3.5 \% \mathrm{NaCl}$ solution. Thus, the Co content has been set as $7 \mathrm{wt} \%$ to achieve the balance between strength and corrosion resistance.

$\mathrm{Ti}$ is the most effective strengthening element in maraging stainless steels. In order to reach a strength target of $1900 \mathrm{MPa}$, Ti content has been set as $1.7 \mathrm{wt} \%$. Considering that the co-addition of Mo and Ti could form a core-shell structure [2] that is good for both strength and toughness, Mo content is set as $3 \mathrm{wt} \%$. Although Mo is good for both strength and corrosion resistance, more Mo addition is infeasible considering the occurrence of delta-ferrite.

The role of $\mathrm{Ni}$ in maraging stainless steel is crucial. On the one hand, Ni could enlarge the austenite region and avoid delta-ferrite formation during cooling via austenite phase field extension. On the other hand, $\mathrm{Ni}$ could form the intermetallic phase, especially form $\eta-\mathrm{Ni}_{3} \mathrm{Ti}$ which is the dominant strengthening precipitate in the Ti-alloyed maraging stainless steels. Also, Ni content should be designed precisely to control the volume fraction of residual austenite that is important for both strength and toughness. Ni content in the IMR steel is designed to be $7.5 \mathrm{wt} \%$.

Finally, in order to guarantee the high fracture toughness, impurities such as $\mathrm{C}, \mathrm{O}$ and $\mathrm{N}$ should be kept less than $30 \mathrm{ppm}$, respectively. Based on the above alloy design analyses, the nominal composition of the IMR steel is designed to be (wt \%) Cr 13.0\%, Ni 7.5\%, Co 7.0\%, Mo 3.0\% and Ti $1.7 \%$.

\section{Experimental Details}

The IMR steel was first melted in a $25 \mathrm{~kg}$ vacuum induction melting furnace and then remelted by vacuum arc melting. $\mathrm{Fe}, \mathrm{Cr}, \mathrm{Ni}, \mathrm{Co}$, Mo and Ti were added in the form of high purity metals $(>99.99 \%)$ to obtain a super-clean steel. Chemical composition of the steel analyzed by ICP (inductively coupled 
plasma) is shown in Table 1. Casting ingot with a diameter of $100 \mathrm{~mm}$ was homogenized at $1200{ }^{\circ} \mathrm{C}$ for $48 \mathrm{~h}$ and then forged into square bars $(20 \mathrm{~mm} \times 20 \mathrm{~mm}$ ). Specimens for tests and microstructure characterizations were subjected to solution annealing at $1050{ }^{\circ} \mathrm{C}$ for $1 \mathrm{~h}$ followed by cryogenic treatment (CT) in liquid nitrogen for $8 \mathrm{~h}$. Finally, aging treatment (AT) with different holding time $\left(10 \mathrm{~min}, 0.5 \mathrm{~h}, 4 \mathrm{~h}, 16 \mathrm{~h}, 40 \mathrm{~h}, 100 \mathrm{~h}\right.$ ) was performed at $480^{\circ} \mathrm{C}$. Other commercial maraging stainless steels were taken from the steel enterprise and were peak aging (PA) treated to reach its highest strength. Afterwards, corrosion current density of all steels has been tested. Mechanical property (fracture toughness and ultimate tensile strength) of three steels (IMR steel, 1RK91 and Custom 475) were tested practically and other steels' mechanical property was taken from the references. In order to guarantee the reliability, three samples have been tested to get the average.

Table 1. Chemical composition of Institute of Metal Research (IMR) steel (wt \%).

\begin{tabular}{ccccccccc}
\hline $\mathbf{C r}$ & $\mathbf{N i}$ & $\mathbf{C o}$ & $\mathbf{M o}$ & $\mathbf{T i}$ & $\mathbf{C}$ & $\mathbf{O}$ & $\mathbf{N}$ & $\mathbf{F e}$ \\
\hline 12.53 & 7.45 & 7.16 & 3.14 & 1.75 & 0.0024 & 0.0028 & 0.0026 & Bal. \\
\hline
\end{tabular}

TEM characterization was conducted using a JEM 2100 transmission microscope (Japan Electron Optical Laboratory, Tokyo, Japan) operated at $200 \mathrm{kV}$. Thin TEM foils were prepared with care for a large electron transparent area and minimum magnetic influence. $3 \mathrm{~mm}$ diameter discs were first mechanically polished to $50 \mu \mathrm{m}$ and then jet electropolished in a bath containing $10 \mathrm{vol} \%$ $\mathrm{HClO}_{4}+90$ vol $\% \mathrm{C}_{2} \mathrm{H}_{5} \mathrm{OH}$ at $-20{ }^{\circ} \mathrm{C}$. Needle-shaped specimens required for APT were prepared by a standard two-step electro-polishing technique. Local electrode atom probe (LEAP) acquisitions were accomplished using a LEAP ${ }^{\mathrm{TM}} 3000 \mathrm{HR}$ under an ultrahigh vacuum of $\sim 1 \times 10^{-8} \mathrm{~Pa}$ at a base temperature of $60 \mathrm{~K}$ with a pulse frequency of $200 \mathrm{kHz}$ and a $20 \%$ pulse fraction. Imago Visualization and Analysis Software (IVAS) version 3.6.2 was used for data reconstruction, composition analysis and the creation of iso-concentration surface.

Tensile tests were conducted according to ASTM E8 on an AG-100KG testing machine (Shimadzu, Tokyo, Japan) at a strain rate of $2.0 \times 10^{-3} \mathrm{~s}^{-1}$ at room temperature. Fracture toughness measurements were performed on a SCHENCK-100KN fatigue test machine (Schenck Process GmbH, Darmstadt, Germany) according to ASTM E399 at a crosshead speed of $0.5 \mathrm{~mm} / \mathrm{min}$. Potentiodynamic polarization (PDP) tests in $3.5 \mathrm{wt} \% \mathrm{NaCl}$ solution were conducted using a PARSTAT4000 electrochemical workstation (Princeton Applied Research, Oak Ridge, TN, USA) with a scan rate of $0.1667 \mathrm{mV} / \mathrm{s}$. The surface area of the working electrodes was reduced to $1.0 \mathrm{~cm}^{2}$ using epoxy resin, in order to avoid the edge effect. A conventional three-electrode (reference, counter and working electrodes) electrochemical cell was used in this study.

\section{Results and Discussion}

\subsection{Microstructure and Properties}

Figure 1 shows the fracture toughness, corrosion resistance and ultimate tensile strength of the IMR steel in comparison with some typical commercial maraging stainless steels. Compared with the commercial maraging stainless steels, IMR steel shows a higher ultimate tensile strength (1920 MPa) which is slightly lower than that of Custom 475 (2000 MPa). In addition to strength, two other critical properties of maraging stainless steels are fracture toughness and corrosion resistance. The corrosion current density obtained from PDP scans was used as an indicator of corrosion resistance. It can be seen clearly that 17-4 PH shows the most outstanding corrosion resistance, which could be attributed to its higher chromium content ( $17 \mathrm{wt} \%)$. In comparison, IMR steel shows an equivalent corrosion resistance to that of 15-5 PH. Moreover, fracture toughness of IMR steel shows notable advantage compared to those maraging stainless steels. In general, strength and toughness show an inverse 
variation trend and it is difficult to improve both simultaneously. However, IMR steel exhibited both high toughness and superior strength, which could be attributed to its unique microstructure.

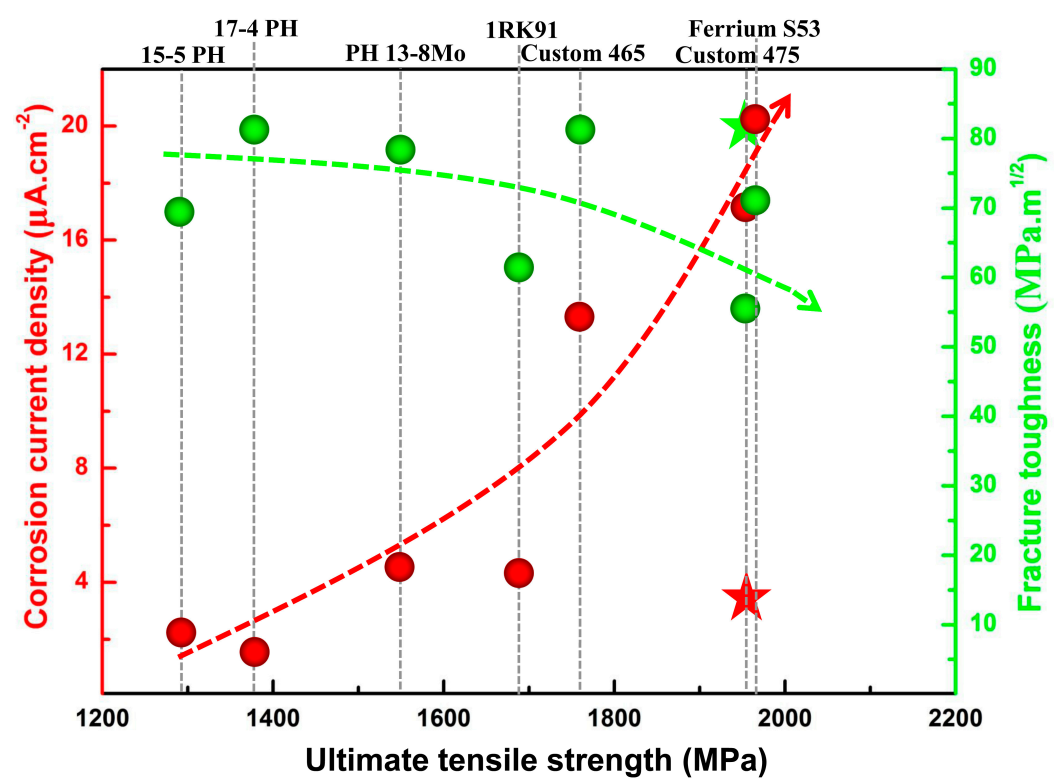

Figure 1. The strength-toughness-corrosion property profiles of the IMR (Institute of Metal Research) steel and comparative maraging stainless steels under peak-aged conditions. Sphere denotes the property of comparative maraging stainless steel and pentacle denotes the property of IMR steel. The mechanical property data of five commercial maraging stainless were taken from references: 15-5 PH [19], 17-4 PH [20], PH 13-8 Mo [21], Custom 465 [22], Ferrium S53 [23].

Figure $2 \mathrm{a}$ is a bright field TEM image of the specimen after cryogenic treatment (CT). Typical martensitic lath is clearly visible while high density dislocations can be found as shown in Figure $2 b$. The high-density dislocations in the matrix can offer preferred nucleation sites and lead to the formation of dispersive precipitates in the following aging process [24,25]. Two types of strengthening precipitates were found in the peak-aged specimen as shown in Figure 2c. According to the high-resolution TEM image (Figure 2(d1,d2)) and the corresponding FFT pattern (Figure 2(d3,d4)), the sphere-like precipitates and rod-like precipitates are identified as Mo-rich phase and $\mathrm{Ni}_{3} \mathrm{Ti}$ phase, respectively.

As a powerful technique to characterize the nano-sized precipitates, atom probe tomography (APT) is characteristic for its near-atomic spatial resolution and can offer the information of the precipitations such as composition, spatial morphology, size, number density, etc., which is beyond the scope of TEM analysis. In this study, regions that contain more than 10 at $\% \mathrm{Mo}$ and 35 at $\% \mathrm{Ni}+\mathrm{Ti}$ are defined as Mo-rich phase and $\mathrm{Ni}_{3} \mathrm{Ti}$ phase, respectively. Figure 3a shows the 3-D reconstruction of the atomic positions of Fe (pink points), isoconcentration surface for regions containing more than 10 at $\%$ Mo (red surfaces) and 35 at \% Ni + Ti (green surfaces). A careful observation of two types of precipitates revealed that each precipitate has two different shapes, sphere-like Mo-rich phase and bar-like $\mathrm{Ni}_{3} \mathrm{Ti}$ phase, as shown in Figure 3b,c, which were also observed by TEM. Meanwhile, Mo-rich phase and $\mathrm{Ni}_{3} \mathrm{Ti}$ phase have another two refined structures which were not observed by TEM. As shown in Figure 3d,e, a ring-like Mo-rich phase and sphere-like $\mathrm{Ni}_{3} \mathrm{Ti}$ phase can be observed. It is believed that small sphere-like $\mathrm{Ni}_{3} \mathrm{Ti}$ phases were formed at the beginning stage of aging treatment and, due to lack of time or hindrance of phase interface, they could not grow to big rod-like precipitates. On the contrary, those with the minimal interface energy between $\mathrm{Ni}_{3} \mathrm{Ti}$ and matrix grew and finally formed rod-like $\mathrm{Ni}_{3} \mathrm{Ti}$ precipitates. In case of Mo-rich phase, except for sphere-like precipitates, ring-like precipitates were also observed located at the interface between $\mathrm{Ni}_{3} \mathrm{Ti}$ and matrix. The corresponding $1-\mathrm{D}$ concentration profile and atomic maps within a selected region crossing the $\mathrm{Ni}_{3} \mathrm{Ti} / \mathrm{matrix}$ interface 
are shown in Figure 4. The region between the two dashed lines corresponds to the Mo-rich phase with thickness of about $5 \mathrm{~nm}$. The results indicate that Mo-rich phase is more likely to nucleate at the $\mathrm{Ni}_{3} \mathrm{Ti} /$ matrix interface, and its forming mechanism will be discussed later.
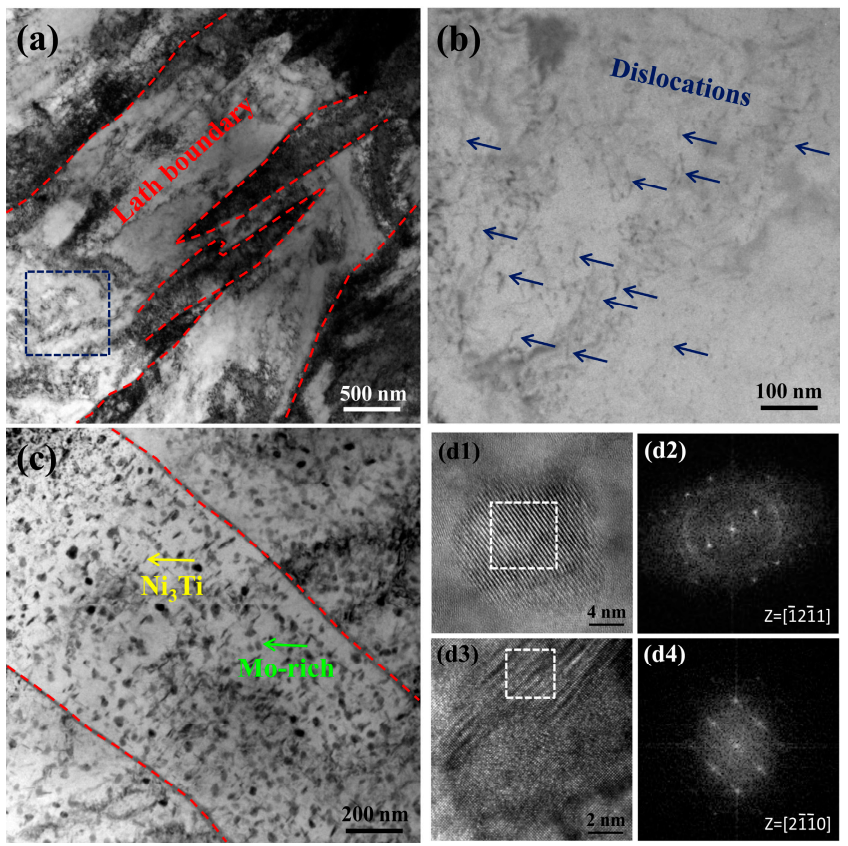

Figure 2. Microstructure characterization by high-resolution TEM (transmission electron microscope). (a) Typical martensitic lath in the specimen after CT (cryogenic treatment) treatment, lath boundary is outlined by red dashed line; (b) Dislocations observation in the region taken from the square in (a); (c) Morphology of $\mathrm{Ni}_{3} \mathrm{Ti}$ and Mo-rich precipitates in the PA-treated specimen; (d1) shows the high-resolution image of Mo-rich precipitate and (d2) shows the corresponding FFT (fast Fourier transform) pattern in the inset. (d3) shows the high-resolution image of $\mathrm{Ni}_{3} \mathrm{Ti}$ precipitate and (d4) shows the corresponding FFT pattern in the inset.
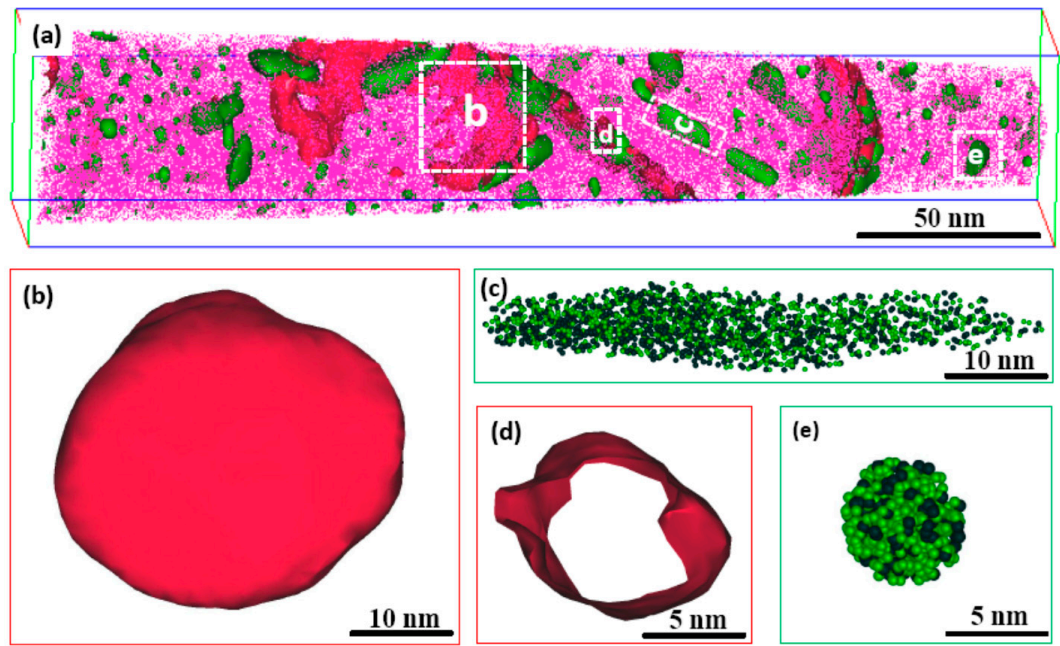

Figure 3. Morphology of precipitates observed by atom probe tomography (APT) analysis in PA-treated specimen. (a) 3-D reconstruction of the atomic positions of Fe (pink points), isoconcentration surface for regions containing more than 10 at \% Mo (red surfaces) and 35 at \% Ni + Ti (green surfaces); (b) Sphere-like Mo-rich phase outlined by 10 at \% Mo isoconcentration surface; (c) Rod-like $\mathrm{Ni}_{3} \mathrm{Ti}$ phase outlined by Ni (green) and Ti (grey) atoms; (d) Flake-like Mo-rich phase outlined by 10 at \% Mo isoconcentration surface; (e) Sphere-like $\mathrm{Ni}_{3} \mathrm{Ti}$ phase outlined by $\mathrm{Ni}$ (green) and $\mathrm{Ti}$ (grey) atoms. 

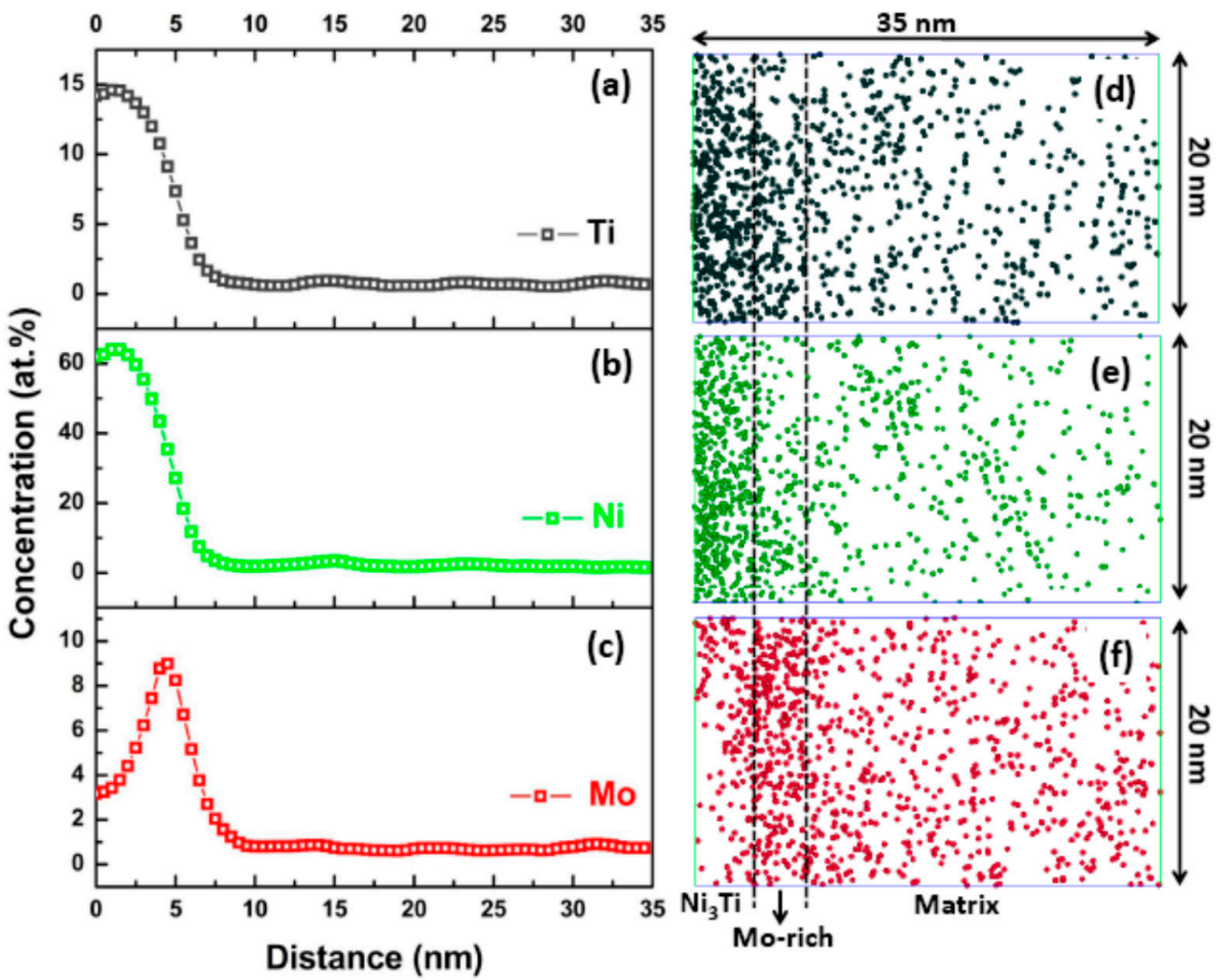

Figure 4. 1-D reconstruction of the atomic positions $(\mathbf{d}-\mathbf{f})$, and the corresponding one-dimensional concentration profile $(\mathbf{a}-\mathbf{c})$, across the $\mathrm{Ni}_{3} \mathrm{Ti} /$ matrix interface for peak-aged specimen.

The good combination of strength and toughness for the IMR steel can be attributed to the following two aspects. First, since Ti precipitates most rapidly, strongly and completely during aging in the maraging stainless steel [26], $\mathrm{Ni}_{3} \mathrm{Ti}$ precipitates make a dominant contribution to the strength. Meanwhile, Mo-rich phase retards the growth of $\mathrm{Ni}_{3} \mathrm{Ti}$ precipitates through its accumulation at the interface [1]. Thus, Mo-rich phase could promote the maintenance of highly dispersive $\mathrm{Ni}_{3} \mathrm{Ti}$ nano-precipitates and enhance the strengthening effect of $\mathrm{Ni}_{3} \mathrm{Ti}$ precipitates. Second, the highly uniform distribution of $\mathrm{Ni}_{3} \mathrm{Ti}$ precipitates effectively reduces stress concentration. In addition, Mo-rich phase at the interface results in a small lattice misfit between $\mathrm{Ni}_{3} \mathrm{Ti}$ and matrix [1]. Thus, the associated elastic interaction between precipitate and dislocation should be lowered. Therefore, the core-shell structure effectively prevents the crack initiation at the precipitate-matrix interface owing to the negligible strain accumulation and thus guarantees a good combination of strength and toughness.

\subsection{Precipitation Mechanism of $\mathrm{Ni}_{3} \mathrm{Ti}$ and Mo-Rich Precipitates}

APT was used to further characterize the evolution of three elements ( $\mathrm{Ni}, \mathrm{Ti}, \mathrm{Mo}$ ) during the aging treatment, and Figure 5 shows the visual atomic position reconstruction. It can be seen clearly that $\mathrm{Ni}$ and Ti show similar distribution positions, which indicates that $\mathrm{Ni}$ and $\mathrm{Ti}$ form clusters together whereas Mo forms cluster separately. Maximum separation envelope methodology (MSEM) was used to further analyze the precipitate kinetics of different clusters. In this method, the spherical volume region around the selected atoms, as defined by a maximum separation distance, $\mathrm{d}_{\max }$, is searched for any other selected solute atoms. The minimum solute atoms number $\left(\mathrm{N}_{\min }\right)$ threshold parameter was used to limit the size of the solute clusters to those more than the threshold value. The cluster numbers were counted based on specific parameters $\left(\mathrm{d}_{\max }\right.$ and $\left.\mathrm{N}_{\min }\right)$ and the cluster density was defined as the ratio of cluster number over the volume of analyzed body. Table 2 shows the statistical results about the clusters density under different aging condition based on the MSEM. 
Both cluster analysis results in Table 2 and atomic positions reconstruction in Figure 5a indicate that no cluster exists in the steel matrix after CT. When aging time was $10 \mathrm{~min}, \mathrm{Ni}$ and Ti clusters occurred as shown in Figure 5(b1,b2), and the cluster density of $\mathrm{Ni}+$ Ti reached $59.92 \times 10^{-5} \mathrm{~nm}^{-3}$ as shown in Table 2. However, no Mo cluster formed after $10 \mathrm{~min}$ according to the cluster analysis results. Cluster density of $\mathrm{Ni}+\mathrm{Ti}$ cluster reached to maximum $\left(116.78 \times 10^{-5} \mathrm{~nm}^{-3}\right)$ after aging for $0.5 \mathrm{~h}$, and with increase of aging time, cluster density decreased slightly as a result of the aggregation and growth of $\mathrm{Ni}_{3} \mathrm{Ti}$ precipitates. According to the cluster analysis results of $\mathrm{Mo}$ in Table 2, it can be found that Mo cluster density only reached to $0.26 \times 10^{-5} \mathrm{~nm}^{-3}$ even after aging for $4 \mathrm{~h}$. Meanwhile, no obvious cluster was observed in the atomic reconstruction (Figure $5(\mathrm{~d} 3)$ ). The maximum value of Mo cluster density was $51.52 \times 10^{-5} \mathrm{~nm}^{-3}$ after aging for $16 \mathrm{~h}$.
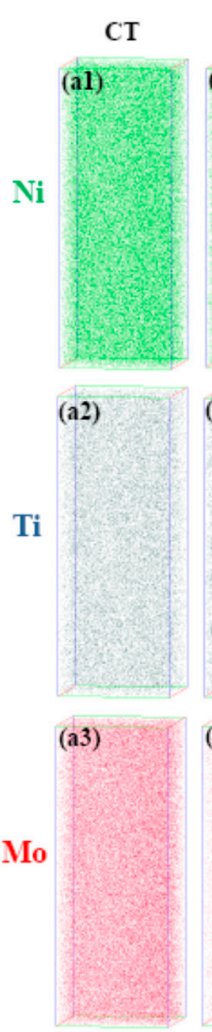
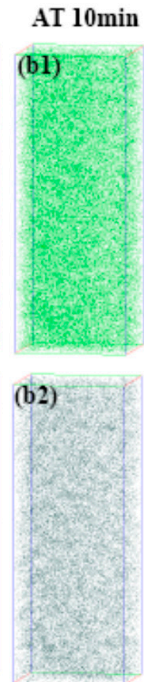

(b3)

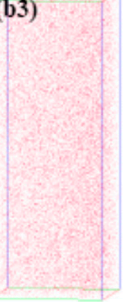

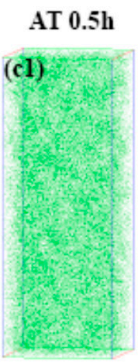

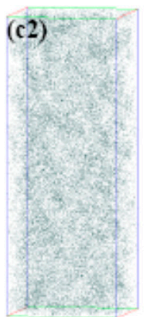

(c3)

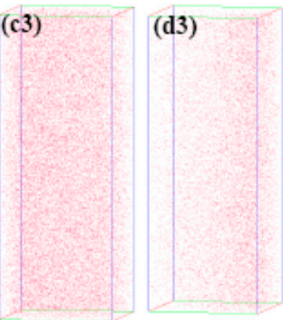

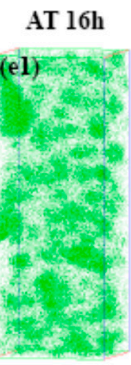

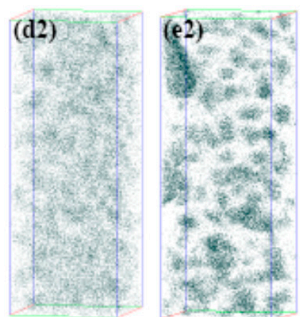

(e3)

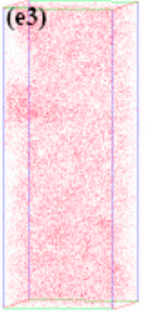

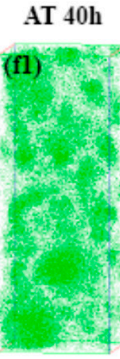
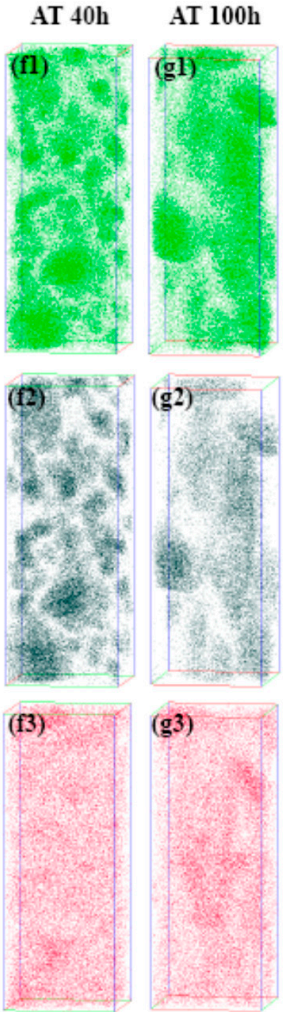
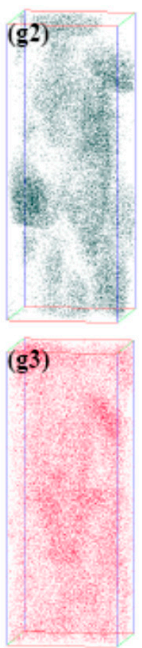

Figure 5. Three-dimensional reconstruction of the atomic positions of $\mathrm{Ni}$ (green points), Ti (grey points) and Mo (red points) for specimens aged at $753 \mathrm{~K}$ for different time. All the analyzed volumes are with the dimension of $30 \times 30 \times 80 \mathrm{~nm}^{3}$.

Table 2. Cluster analysis of specimens under different aging conditions. $\left(\mathrm{Ni}+\right.$ Ti cluster: $\mathrm{d}_{\max }=0.5$, $\mathrm{N}_{\min }=100$; Mo cluster: $\mathrm{d}_{\max }=0.5, \mathrm{~N}_{\min }=10$ ).

\begin{tabular}{cccccccc}
\hline Items & CT & AT 10 $\mathbf{~ m i n}$ & AT $\mathbf{0 . 5} \mathbf{h}$ & AT $\mathbf{~ h ~}$ & AT 16 h & AT $\mathbf{4 0} \mathbf{h}$ & AT 100 $\mathbf{~}$ \\
\hline Volume of analyzed body $\left(\mathrm{nm}^{3}\right)$ & 638,160 & 745,996 & 554,895 & 757,120 & 772,475 & 874,380 & 799,779 \\
$\mathrm{Ni}+$ Ti cluster density $\left(10^{-5} \mathrm{~nm}^{-3}\right)$ & 0 & 59.92 & 116.78 & 114.51 & 79.74 & 56.04 & 15.63 \\
Mo cluster density $\left(10^{-5} \mathrm{~nm}^{-3}\right)$ & 0 & 0 & 0 & 0.26 & 51.52 & 3.09 & 9.38 \\
\hline
\end{tabular}

The results indicate that $\mathrm{Ni}$ and $\mathrm{Ti}$ showed much quicker aging response than Mo at the early aging stage. Considering the diffusion coefficients of the portioning elements ( $\mathrm{Ni}, \mathrm{Ti}, \mathrm{Mo}, \mathrm{Fe}$ ) in the $\alpha$-Fe matrix [27-29], the diffusivity of Mo is much lower than that of the other elements. This indicates that Mo acts as a kinetically controlling element for the precipitation process, as revealed by the fact that Mo is rejected from the precipitate into the matrix, accumulating before the $\mathrm{Ni}_{3} \mathrm{Ti} /$ matrix interface. 
Figure 6 shows the distribution characteristics of $\mathrm{Ni}_{3} \mathrm{Ti}$ phase outlined by green $\mathrm{Ni}+\mathrm{Ti} 35$ at $\%$ isoconcentration surface and Mo-rich phase outlined by red Mo 5 at \% isoconcentration surface at different aging stages. When the aging time was $0.5 \mathrm{~h}$, sphere-like $\mathrm{Ni}_{3} \mathrm{Ti}$ particles are evident, as shown in Figure $6 \mathrm{~b}$. When the aging time extended, a further growth of particles seems to occur, and their average diameter also increases. But the evolution of Mo-rich phase was different, as no Mo 5 at \% isoconcentration surface was detected in the specimen aged for $4 \mathrm{~h}$, as shown in Figure $6 \mathrm{c}$, which could be attributed to a low Mo concentration at $\mathrm{Ni}_{3} \mathrm{Ti}$ /matrix interface. According to the proximity histogram analysis shown in Figure $7 \mathrm{a}$, the Mo concentration at $\mathrm{Ni}_{3} \mathrm{Ti} /$ matrix interface approximates to the average concentration of Mo in the matrix (1.58 at \%). When aging time prolonged to $40 \mathrm{~h}$ (Figure $7 \mathrm{~b}$ ) and $100 \mathrm{~h}$ (Figure 7c), the Mo concentration at $\mathrm{Ni}_{3} \mathrm{Ti} /$ matrix interface increases to 2.09 at \% and 3.06 at $\%$, respectively.
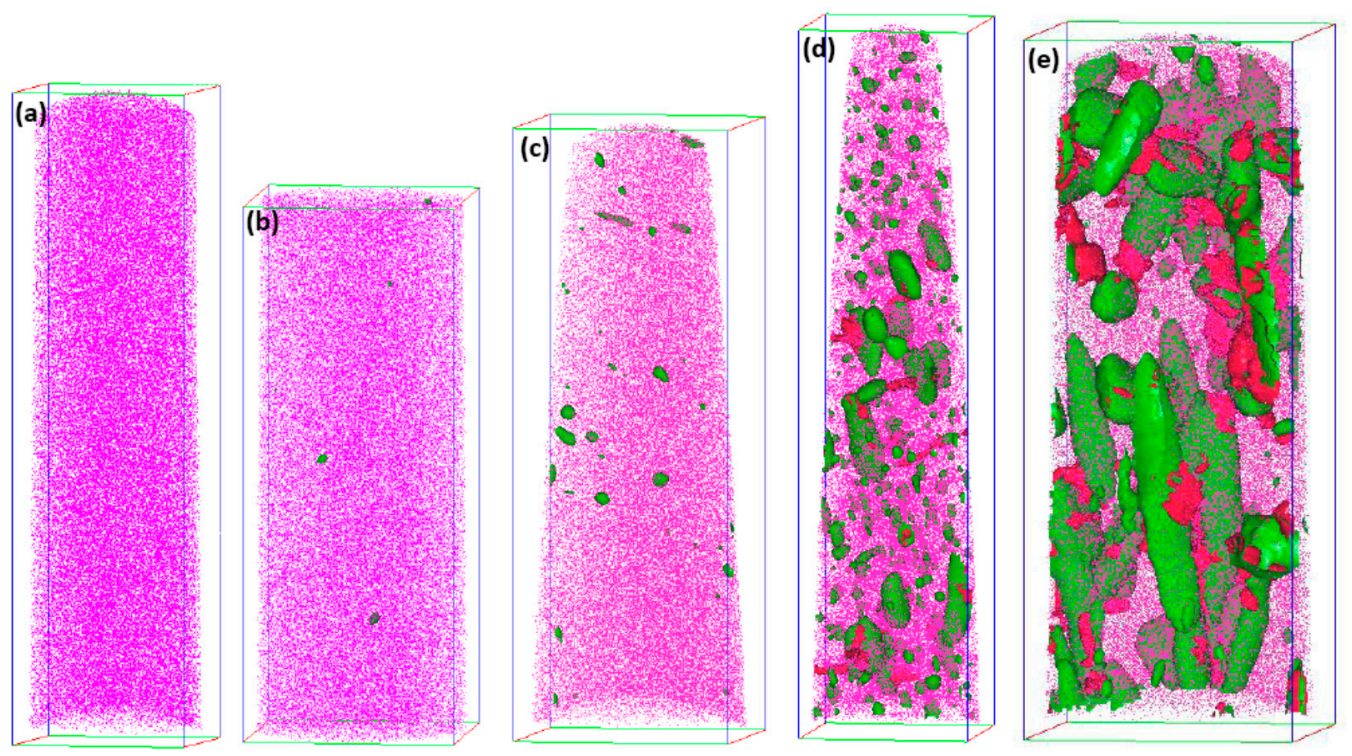

Figure 6. Three-dimensional reconstruction of the atomic positions of Fe (purple pints) and isoconcentration surface for regions containing more than 35 at $\% \mathrm{Ni}+\mathrm{Ti}$ (green surfaces) and 5 at \% Mo (red surfaces) for specimens (a) aged for $10 \mathrm{~min}$; (b) aged for $0.5 \mathrm{~h}$; (c) aged for $4 \mathrm{~h}$; (d) aged for $40 \mathrm{~h}$; (e) aged for $100 \mathrm{~h}$. Bounding box size: (a) $58 \times 59 \times 218 \mathrm{~nm}^{3}$; (b) $55 \times 55 \times 144 \mathrm{~nm}^{3}$; (c) $64 \times 65 \times 182 \mathrm{~nm}^{3}$; (d) $59 \times 60 \times 247 \mathrm{~nm}^{3}$; (e) $67 \times 69 \times 173 \mathrm{~nm}^{3}$.
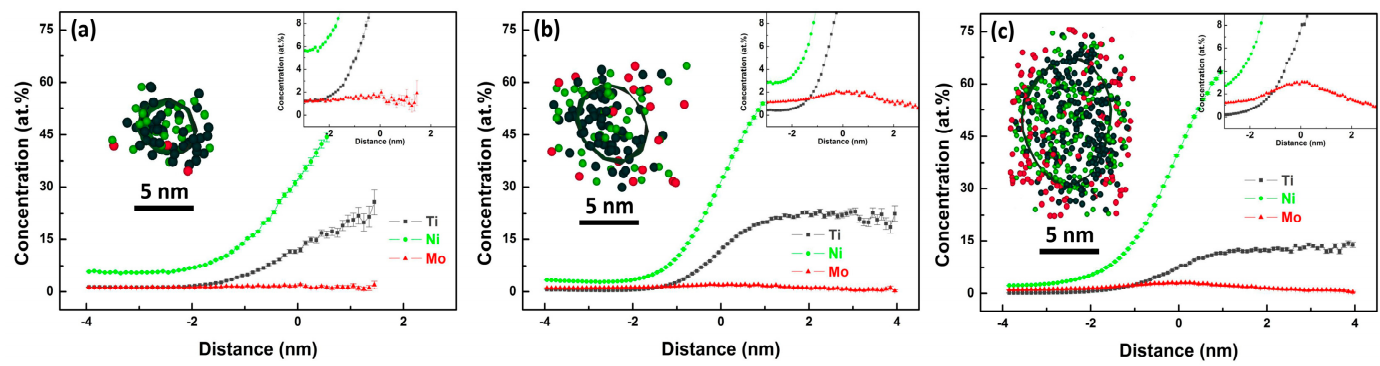

Figure 7. Proximity histograms of $\mathrm{Ni}_{3} \mathrm{Ti}$ precipitate in different specimens (a) aged for $4 \mathrm{~h}$; (b) aged for $16 \mathrm{~h}$; (c) aged for $100 \mathrm{~h}$. The inserts show the $1 \mathrm{~nm}$ thick atom maps through the centers of representative $\mathrm{Ni}_{3} \mathrm{Ti}$ precipitate in specimens under different aging conditions (Ni for green sphere, Ti for grey sphere, Mo for red sphere).

Since the diffusivity of Mo is much lower than those of $\mathrm{Ni}$ and $\mathrm{Ti}$, this indicates that $\mathrm{Ni}_{3} \mathrm{Ti}^{\mathrm{N}}$ nucleates headmost and will seize most prior nucleation sites such as grain boundary, blocky/lath boundary and dislocation. Considering that these defects are also favorable diffusion paths, a low 
nucleation rate of Mo-rich phase can be predicted. This well explains the larger size and lower number density Mo-rich phase. As shown in Figure 3a, the dimension of sphere-like Mo-rich phase is almost similar to the cross section $\left(\sim 50 \times 50 \mathrm{~nm}^{2}\right)$ of the APT analytical body. Attributed to the size limitation of APT analytical body, sphere-like Mo-rich phase was not included in the analytical body, as shown in Figure 6d,e. This also results in an anomaly phenomenon in Table 2 that Mo cluster density had a sharp decrease after aging time reached to $40 \mathrm{~h}$ and $100 \mathrm{~h}$.

Based on the above characterization on the formation and evolution of the $\mathrm{Ni}_{3} \mathrm{Ti}$ and Mo-rich phases, the precipitation mechanism in the new maraging stainless steel can be revealed as follows and schematically illustrated in Figure 8. At the initial stage of aging, Ni and Ti firstly precipitate out of the supersaturated solid solution to form $\mathrm{Ni}+\mathrm{Ti}$ cluster together. During the rapid initial growth process of $\mathrm{Ni}_{3} \mathrm{Ti}$, Mo solutes are rejected from $\mathrm{Ni}_{3} \mathrm{Ti}$ and finally segregate at the $\mathrm{Ni}_{3} \mathrm{Ti} /$ matrix interface. Since the precipitation of $\mathrm{Ni}_{3} \mathrm{Ti}$ has seized most prior nucleation sites and favorable diffusion paths, such as grain boundary, blocky/lath boundary and dislocation, Mo-rich phase is inclined to nucleate at the $\mathrm{Ni}_{3} \mathrm{Ti} /$ matrix interface as a result of Mo atoms accumulation. After stable Mo-rich phase nucleation occurs, considering that the diffusion of Mo is difficult, most nuclei grow up slightly to form final flake-like Mo-rich phase adjacent to $\mathrm{Ni}_{3} \mathrm{Ti}$ phase. Thus, the flake-like Mo-rich phase and $\mathrm{Ni}_{3} \mathrm{Ti}_{ }$hase form a core-shell structure together. In different sites, portion of nucleus grow up drastically to form large size sphere-like Mo-rich phase and even build a crosslink to each other.

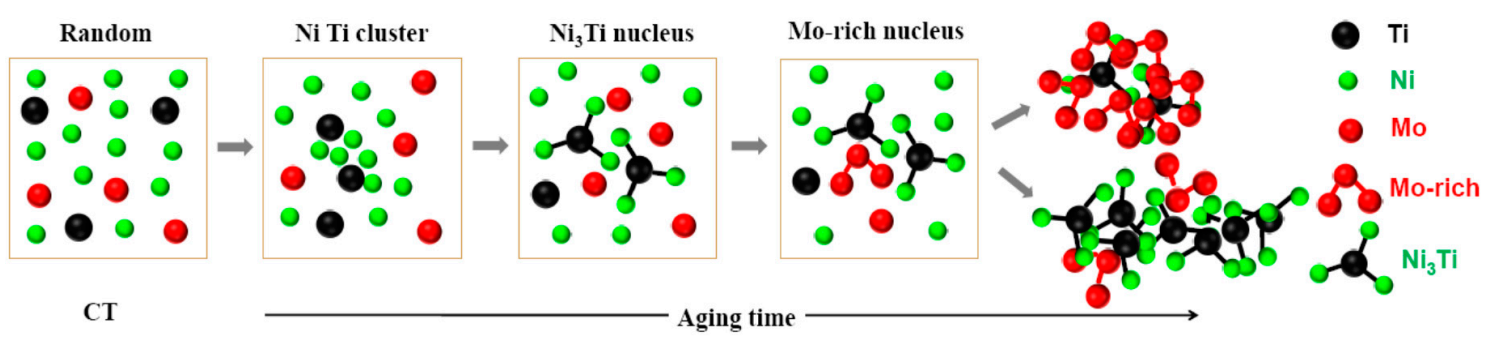

Figure 8. Schematics showing precipitation mechanism of $\mathrm{Ni}_{3} \mathrm{Ti}$ and Mo-rich phases in the new maraging stainless steel.

\section{Conclusions}

This study presents an understanding of the mechanism of the evolution of precipitation in a new maraging stainless steel. The features of different kind of precipitations are carefully characterized at atomic scale based on combination of APT and TEM analyses. The following conclusions are drawn from the study:

A new maraging stainless steel with high strength (above $1920 \mathrm{MPa}$ ), high toughness $\left(\sim 80 \mathrm{MPa} \cdot \mathrm{m}^{1 / 2}\right)$ and superior corrosion resistance (comparable to $\left.15-5 \mathrm{PH}\right)$ was developed. The new maraging stainless steel is strengthened by two dominant strengthening precipitations including $\mathrm{Ni}_{3} \mathrm{Ti}$ and Mo-rich phases. Different morphologies of these two strengthening precipitates (rod-like and sphere-like $\mathrm{Ni}_{3} \mathrm{Ti}$ phase, flake-like and sphere-like Mo-rich phase) were observed by APT.

In the aging process, $\mathrm{Ni}$ and $\mathrm{Ti}$ solutes show a much quicker precipitation response than Mo solute. Associated with morphology observation and cluster analysis, the precipitation mechanism is succinctly proposed as: supersaturated solid solution $\rightarrow \mathrm{Ni}+\mathrm{Ti}$ cluster $\rightarrow \mathrm{Ni}_{3} \mathrm{Ti}$ nucleus $\rightarrow \mathrm{Ni}_{3} \mathrm{Ti}$ nucleus and Mo-rich segregation $\rightarrow$ core-shell structure $\left(\mathrm{Ni}_{3} \mathrm{Ti}\right.$ phase and flake-like Mo-rich phase) or large sphere-like Mo-rich phase depending on the grow up process of Mo-rich nucleus.

Acknowledgments: This research is sponsored by Youth Innovation Promotion Association of Chinese Academy of Sciences (2017233), Innovation Project of Institute of Metal Research (2015-ZD04) and National Natural Science Foundation of China Research Fund for International Young Scientists (No. 51750110515). We acknowledge Wenqing Liu for APT experiment support and relevant discussion on the data analysis. 
Author Contributions: Ke Yang, Zhouhua Jiang and Yiyin Shan designed the project. Wei Yan, M. Babar Shahzad and Wei Wang produced the samples used in this study. Jialong Tian peformed the microstructural analyses and the properties test. All authors contributed to the interpretation of the results and the writing of the manuscript.

Conflicts of Interest: The authors declare no conflict of interest.

\section{References}

1. Jiang, S.; Wang, H.; Wu, Y.; Liu, X.J.; Chen, H.G.; Yao, M.J.; Gault, B.; Ponge, D.; Raabe, D.; Hirata, A.; et al. Ultrastrong steel via minimal lattice misfit and high-density nanoprecipitation. Nature 2017, 544, 460-464. [CrossRef] [PubMed]

2. $\quad$ Li, Y.C.; Yan, W.; Cotton, J.D.; Ryan, G.J.; Shen, Y.F.; Wang, W.; Shan, Y.Y.; Yang, K. A new 1.9 GPa maraging stainless steel strengthened by multiple precipitating species. Mater. Des. 2015, 82, 56-63. [CrossRef]

3. Xu, W.; Rivera-Díaz-del-Castillo, P.E.J.; Yan, W.; Yang, K.; Martín, D.S.; Kestens, L.A.I.; van der Zwaag, S. A new ultrahigh-strength stainless steel strengthened by various coexisting nanoprecipitates. Acta Mater. 2010, 58, 4067-4075. [CrossRef]

4. Liu, Z.B.; Liang, J.X.; Zhang, X.L.; Yang, Z.Y.; Sun, G.Q. The development and application of high-performance ultra-high strength stainless steel subject to marine environment. Mater. Sci. Forum 2014, 783-786, 867-874. [CrossRef]

5. Guo, Z.; Sha, W.; Vaumousse, D. Microstructural evolution in a PH13-8 stainless steel after ageing. Acta Mater. 2003, 51, 101-116. [CrossRef]

6. Hättestrand, M.; Nilsson, J.O.; Stiller, K.; Liu, P.; Andersson, M. Precipitation hardening in a 12\%-9\%Ni-4\%Mo-2\%Cu stainless steel. Acta Mater. 2004, 52, 1023-1037. [CrossRef]

7. Jiao, Z.B.; Luan, J.H.; Miller, M.K.; Liu, C.T. Precipitation mechanism and mechanical properties of an ultra-high strength steel hardened by nanoscale NiAl and Cu particles. Atca Mater. 2015, 97, 58-67. [CrossRef]

8. Murthy, A.S.; Medvedeva, J.E.; Isheim, D.; Lekakh, S.L.; Richards, V.L.; Van Aken, D.C. Copper precipitation in cobalt-alloyed precipitation-hardened stainless steel. Scr. Mater. 2012, 66, 943-946. [CrossRef]

9. Leitner, H.; Schnitzer, R.; Schober, M.; Zinner, S. Precipitate modification in PH13-8 Mo type maraging steel. Acta Mater. 2011, 59, 5012-5022. [CrossRef]

10. Murayama, M.; Katayama, Y.; Hono, K. Microstructural evolution in a 17-4 PH stainless steel after aging at $400{ }^{\circ}$ C. Metall. Mater. Trans. A 1999, 30A, 345-353. [CrossRef]

11. Speich, G.R.; Dabkowski, D.S.; Porter, L.F. Strength and toughness of Fe-10Ni alloys containing C, Cr, Mo, and Co. Metall. Trans. 1973, 4, 303-315. [CrossRef]

12. Squires, D.R.; Wilson, F.G.; Wilson, E.A. The influence of Mo and Co on the embrittlement of an Fe-Ni-Mn alloy. Metall. Trans. 1974, 5, 2569-2578. [CrossRef]

13. Kwon, H.; Lee, J.H.; Lee, K.B.; Kwon, H.; Kim, C.M.; Yang, H.R. Effects of Co and Ni on secondary hardening and fracture behavior of martensitic steels bearing W and Cr. Metall. Mater. Trans. A 1998, 29, 397-401. [CrossRef]

14. Kwon, H.; Lee, J.H.; Lee, K.B.; Kwon, H.; Kim, C.M.; Yang, H.R. Effect of alloying additions on secondary hardening behavior of mo-containing steels. Metall. Mater. Trans. A 1997, 28, 621-627. [CrossRef]

15. Nakamichi, H.; Sato, K.; Miyata, Y.; Kimura, M.; Masamura, K. Quantitative analysis of Cr-depleted zone morphology in low carbon martensitic stainless steel using Fe-(S)TEM. Corros. Sci. 2008, 50, 309-315. [CrossRef]

16. Ma, X.; Wang, L.; Subramanian, S.V.; Liu, C. Studies on $\mathrm{Nb}$ microalloying of $13 \mathrm{Cr}$ super martensitic stainless steel. Metall. Mater. Trans. A 2012, 43A, 4475-4486. [CrossRef]

17. Tian, J.L.; Wang, W.; Yin, L.C.; Yan, W.; Shan, Y.Y.; Yang, K. Three dimensional atom probe and first-principles studies on spinodal decomposition of $\mathrm{Cr}$ in a Co-Alloyed maraging stainless steel. Scr. Mater. 2016, 121, 37-41. [CrossRef]

18. Lo, K.H.; Shek, C.H.; Lai, J.K.L. Recent developments in stainless steels. Mater. Sci. Eng. R 2009, 65, 39-104. [CrossRef]

19. Abdelshehid, M.; Mahmodieh, K.; Mori, K.; Chen, L.; Stoyanov, P.; Davlantes, D.; Foyos, J.; Ogren, J.; Clark, R., Jr.; Es-Said, O.S. On the correlation between fracture toughness and precipitation hardening heat treatment in 15-5PH stainless steel. Eng. Fail. Anal. 2007, 14, 626-631. [CrossRef] 
20. Rack, H.J.; Kalish, D. The strength, fracture toughness, and low cycle fatigue behavior of 17-4 PH stainless steel. Metall. Trans. 1974, 5, 1595-1605. [CrossRef]

21. Rossi, D.J.; Rossi, J.D. PH stainless steel is tougher than you thought. Adv. Mater. Process. 1987, 131, 45-47.

22. Wert, D.E.; Disabella, R.P. Strong, corrosion-resistance stainless steel. Adv. Mater. Process. 2006, 164, 34-36.

23. Kuehmann, C.; Tufts, B.; Trester, P. Computational design for ultra high-strength alloy. Adv. Mater. Process. 2008, 166, 37-40.

24. Cahn, J.W. Nucleation on dislocations. Acta Metall. 1957, 5, 169-172. [CrossRef]

25. Druzhkov, A.P.; Perminov, D.A. Positron annihilation studies of microstructural changes in cold-worked Fe-Ni-base aging alloys. Mater. Sci. Eng. A 2010, 527, 3877-3885. [CrossRef]

26. Sha, W.; Cerezo, A.; Smith, G.D.W. Phase chemistry and precipitation reactions in maraging steels: Part IV. Discussion and conclusions. Metall. Trans. A 1993, 24, 1251-1256. [CrossRef]

27. Nitta, H.; Yamamoto, T.; Kanno, R.; Takasawa, K.; Iida, T.; Yamazaki, Y.; Ogu, S.; Iijima, Y. Diffusion of molybdenum in $\alpha$-iron. Acta Mater. 2002, 50, 4117-4125. [CrossRef]

28. Shapovalov, V.P.; Kurasov, A.N. Diffusion of titanium in iron. Met. Sci. Heat Treat. 1975, 17, $803-805$. [CrossRef]

29. Hettich, G.; Mehrer, H.; Maier, K. Self-Diffusion in ferromagnetic $\alpha$-iron. Scr. Metall. 1977, 11, 795-802. [CrossRef]

(C) 2017 by the authors. Licensee MDPI, Basel, Switzerland. This article is an open access article distributed under the terms and conditions of the Creative Commons Attribution (CC BY) license (http:/ / creativecommons.org/licenses/by/4.0/). 